\title{
INTERAMNA LIRENAS AND ITS TERRITORY (COMUNE DI PIGNATARO INTERAMNA, PROVINCIA DI FROSINONE, REGIONE LAZIO)
}

doi: $10.1017 /$ S0068246216000246

The fieldwork project at Interamna Lirenas has run for six consecutive years from 2009. Since its inception, our research has endeavoured to combine an integrated array of field methodologies including geophysical survey, field walking and (since 2013) excavation (Bellini et al., 2012; 2013; 2014; Ballantyne et al., 2015). The range of data so collected not only has prompted a fundamental change in our understanding of the long-term development of the site and its hinterland (for example, moving away from narratives of early decline), but it has also further reinforced our belief in the enormous informative potential of large-scale remote sensing (for example, making it possible to cast the results of trench excavation and surface collections against a much broader and more complex interpretive canvas).

This methodological awareness provided the intellectual background for a new important phase in our research. As part of the AHRC-funded 'Beneath the Surface of Roman Republican Cities' project (2015-17), in July 2015 we launched a fullcoverage ground-penetrating radar (GPR) survey of the entire urban area of Interamna Lirenas (c. $25 \mathrm{ha}$ ), combined with a systematic sample surface collection and testpitting of the plough-soil. The geophysical prospection is being carried out in collaboration with the University of Ghent and employs a custom-made GPR system as at Falerii (see above).

The 2015 season has therefore adopted a three-pronged approach: (a) continuation of the excavation of the theatre, (b) GPR prospection and (c) systematic surface collections across the site (including test-pitting). Preliminary results from (b) will be mentioned briefly as the resulting images are currently under study, whereas (c) will not be discussed as the study of the collected materials is still in progress.

Following from the results of the 2014 campaign, we decided not to extend the trench, but rather to explore fully the deeper levels within the theatre's cavea and underneath the pulpitum in order to get to the floor of the orchestra and investigate its structural relationship with the rest of the building (Fig. 1). Beneath a phase of later spoliation, attested by large limestone blocks stacked against each other (which we further documented - and removed) lay several layers largely made up of incoherent and highly fragmented debris (that is, dumped into the cavea rather than an in situ collapse), which feature a high level of residuality (for example, pottery chronology ranging from the Republican period to late antiquity). At a depth of more than $2 \mathrm{~m}$ below the surface, there was still no trace of the orchestra's floor (most likely robbed). It also became clear that this sector of the theatre had been radically transformed following its demise as an entertainment building: a section of the scaena (broadly corresponding to the southeast hospitalium passage) had been cut through and completely removed up to - and including - the foundations. This created a deep and wide opening, perfectly in line with the missing wall supporting the upper cavea (a remarkable 'absence' which was first noted in the previous season): these two features give the impression that a broad passageway had been created through the theatre in order to allow a better access in and out from the cavea (for carts?), where systematic spoliation activities did probably take place after the theatre's abandonment (for example, breaking down seats in smaller pieces to be burned into a possible limekiln nearby). The analysis of archaeobotanical samples from some of the deeper layers confirmed their heterogeneous 


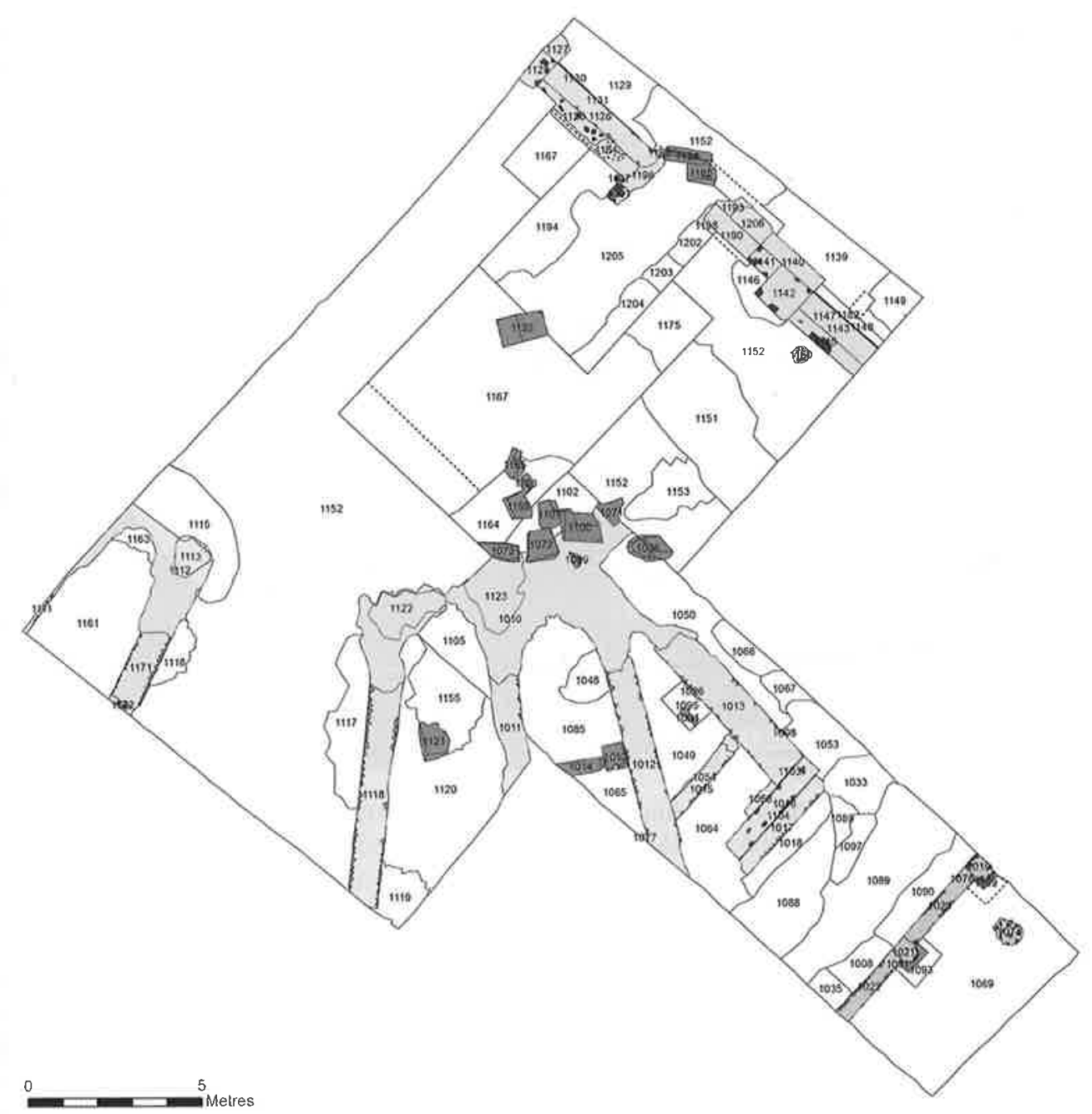

Fig. 1. Plan of the excavation at the end of the 2015 season.

composition and their likely secondary deposition, thus further corroborating our hypothesis that the cavea began to be used as a dump and gradually filled up as a result. A first assessment of the state of the frescoes identified in 2014 was also carried out: it was found that they are preserved for a height of $c .30 \mathrm{~cm}$ above a likely floor level, being decorated in their visible part with simple horizontal bands of colour (red and - possibly - yellow).

As far as the GPR survey is concerned, the 2015 season managed to cover a bit more than 8 ha, including the area immediately to the northwest and southeast of the forum. The resulting preliminary depth-slices broadly confirm the main street layout that magnetometry had first identified in 2010-12, but add considerably more detail in terms of the internal articulation of the insulae (Fig. 2). These images are currently being processed and require more study before more definitive interpretations can be put forward. Our understanding of the plan of the theatre has been considerably 


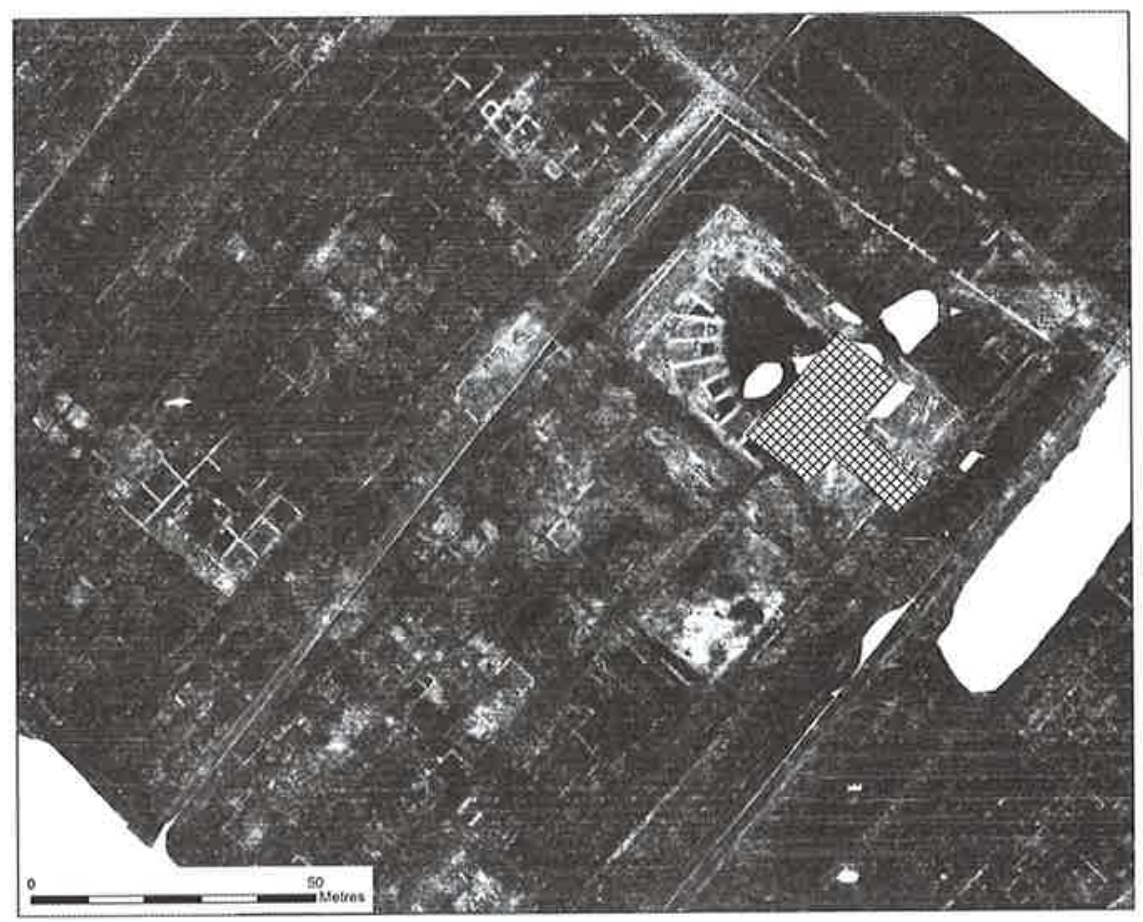

Fig. 2. Some preliminary results of the GPR survey with the location of the excavation (cross-hatching).

improved: it is clear now that the cavea is encased within a rectangular building (c. $45 \times$ $26 \mathrm{~m}$ ), surrounded on at least three sides by a portico (probably defined by the same opus reticulatum wall with regularly spaced brick semi-columns known from the 2013 excavation season). Similar layouts are known from Augusta Praetoria (Augustan) and Luna (Julio-Claudian), although it seems still premature to revise our original interpretation in favour of more specific architectural forms (odeum, theatrum tectum: discussion in Sear, 2006: 39-43). Worthy of note is another rectangular building (c. $26 \times 18 \mathrm{~m}$ ), which stood to the immediate south of the theatre, bordering the forum and featuring quite extensive remains of the original flooring together with possible traces of an internal colonnade (basilica?).

On the whole the 2015 season has proved immensely informative, adding much to our understanding of the post-abandonment phases of the theatre, its overall layout and its place within the broader urban texture.

\section{Acknowledgements}

The project is run in collaboration with the British School at Rome and the Soprintendenza Archeologia del Lazio e dell'Etruria Meridionale. It has benefited from the generous support of the Arts and Humanities Research Council, the British Academy, the Leverhulme Trust, the Faculty of Classics (University of Cambridge), the McDonald Institute for Archaeological Research (University of Cambridge) and the Comune di Pignataro Interamna. The authors wish to extend their gratitude to Dr Nick Soderberg, who carried out the systematic surface collections and test-pitting across the 
site, and to the undergraduate students of the Faculty of Classics generally, who gave a fundamental and enthusiastic contribution to the success of the campaign.

\section{References}

Ballantyne, R., Bellini, G.R., Hay, S., Launaro, A., Leone, N. and Millett, M. (2015) Interamna Lirenas. Papers of the British School at Rome 83: 299-302.

Bellini, G.R., Hay, S., Launaro, A., Leone, N. and Millett, M. (2012) Interamna Lirenas. Papers of the British School at Rome 80: 358-60.

Bellini, G.R., Hay, S., Launaro, A., Leone, N. and Millett, M. (2013) Interamna Lirenas. Papers of the British School at Rome 81: 358-60.

Bellini, G.R., Hay, S., Launaro, A., Leone, N. and Millett, M. (2014) Interamna Lirenas. Papers of the British School at Rome 82: 326-31.

Bellini, G.R, Launaro, A. and Millett, M. (2014) Roman colonial landscapes: Interamna Lirenas and its territory through Antiquity. In T.D. Stek and J. Pelgrom (eds), Roman Republican Colonisation: New Perspectives from Archaeology and Ancient History (Papers of the Royal Netherlands Institute in Rome 62): 255-75. Rome, The Royal Netherlands Institute in Rome. Sear, F. (2006) Roman Theatres: An Architectural Study. Oxford, Oxford University Press.

Rachel Ballantyne, Giovanna R. Bellini, James Hales, Alessandro launaro, Ninetta Leone, Martin Millett, Lieven Verdonck AND FRANK VERMEULEN

(Pitt-Rivers Laboratory for Bioarchaeology, McDonald Institute for Archaeological Research, University of Cambridge; Soprintendenza Archeologia del Lazio e dell'Etruria Meridionale; Institute of Archaeology, University College London; Faculty of Classics, University of Cambridge; Faculty of Classics, University of Cambridge; Faculty of Classics, University of Cambridge; Department of Archaeology, Ghent University;

Department of Archaeology, Ghent University) rmb51@cam.ac.uk; giovannarita.bellini@beniculturali.it; j.hales@ucl.ac.uk; al506@cam.ac.uk;nl343@cam.ac.uk; mim62@cam.ac.uk; lieven.verdonck@ugent.be; frank.vermeulen@ugent.be 